\title{
A TRANSDISCIPLINARIDADE NO DESENVOLVIMENTO DA POLÍTICA PÚBLICA DE REGULARIZAÇÃO FUNDIÁRIA: CONDIÇÃO DE EFETIVIDADE DO DIREITO À MORADIA NOS ASSENTAMENTOS URBANOS INFORMAIS
}

\author{
Cintia Maria Scheid*
}

Sumário: 1 Introdução; 2 A dignidade da pessoa humana, no direito à moradia, a partir das condições mínimas de habitabilidade; 3 Breve panorama da política pública de regularização fundiária no Brasil; 4 Política pública transdisciplinar de regularização fundiária e a efetividade do direito à moradia; 5 Considerações finais.

Resumo: O grave problema da moradia nos assentamentos urbanos informais é resultado de décadas de desenvolvimento urbano irregular, decorrente da busca pela moradia urbana pela população de baixa renda. Ao mesmo tempo em que ocorreram à revelia das determinações legais urbanísticas, o Poder Público e a sociedade não se sensibilizaram a ponto de tomar, oportunamente, as medidas cabíveis para evitar a situação consolidada e caótica em que hoje se encontram os grandes centros urbanos. Às pessoas que vivem nesses assentamentos não foram garantidas as condições para uma moradia digna, fazendo das cidades brasileiras o berço da desigualdade e da segregação social e urbana. Os programas oficiais de financiamento habitacional, por seu turno, demonstraram-se inadequados, pois atuam com a lógica do mercado, inaplicável à população de baixa renda. Nessa perspectiva, a regularização fundiária urbana surge como a alternativa mais condizente para fazer frente a essas mazelas. Contudo, deve ser elaborada e desenvolvida sobre as necessidades mínimas de habitabilidade, que envolvem aspectos materiais da moradia e subjetivos dos moradores. Para tanto, a elaboração e o desenvolvimento da política de regularização fundiária urbana deve ser transdisciplinar, tendo como protagonista a população envolvida. Assim, a hipótese a ser

\footnotetext{
Doutoranda em Direito pela Faculdade Autônoma de Direito de São Paulo (FADISP) - Área de Concentração: Função Social no Direito Constitucional - Linha de Pesquisa: Constitucionalização dos Institutos de Direito Privado. Mestre em Direito pela Universidade de Santa Cruz do Sul - UNISC - Área de concentração: Direitos Sociais e Políticas Públicas - Linha de Pesquisa: Políticas Públicas de Inclusão Social. Especialista em Direito Registral Imobiliário pela UNIASSELVI - Centro Universitário Leonardo da Vinci. Especialista em Direito Notarial e Registral pela Universidade do Sul de Santa Catarina - UNISUL. Especialista em Direito do Estado pela Universidade Federal do Rio Grande do Sul - UFRGS. MBA pela Escuela Superior de Administración y Dirección de Empresas - ESADE Barcelona, Espanha. Titular do $1^{\circ}$ Serviço de Registro Civil das Pessoas Naturais e $5^{\circ}$ Tabelionato de Notas de Maringá, Paraná.
} 
desenvolvida neste trabalho é a de que a política de regularização fundiária urbana realizada sob a ótica da transdisciplinaridade é pressuposto para a efetiva proteção e promoção do direito à moradia minimamente digna nos assentamentos urbanos informais. O método utilizado para o desenvolvimento desta pesquisa foi o dedutivo, mediante pesquisa de bibliográfica.

Palavras-chave: Efetividade do direito à moradia. Regularização fundiária urbana. Transdisciplinaridade.

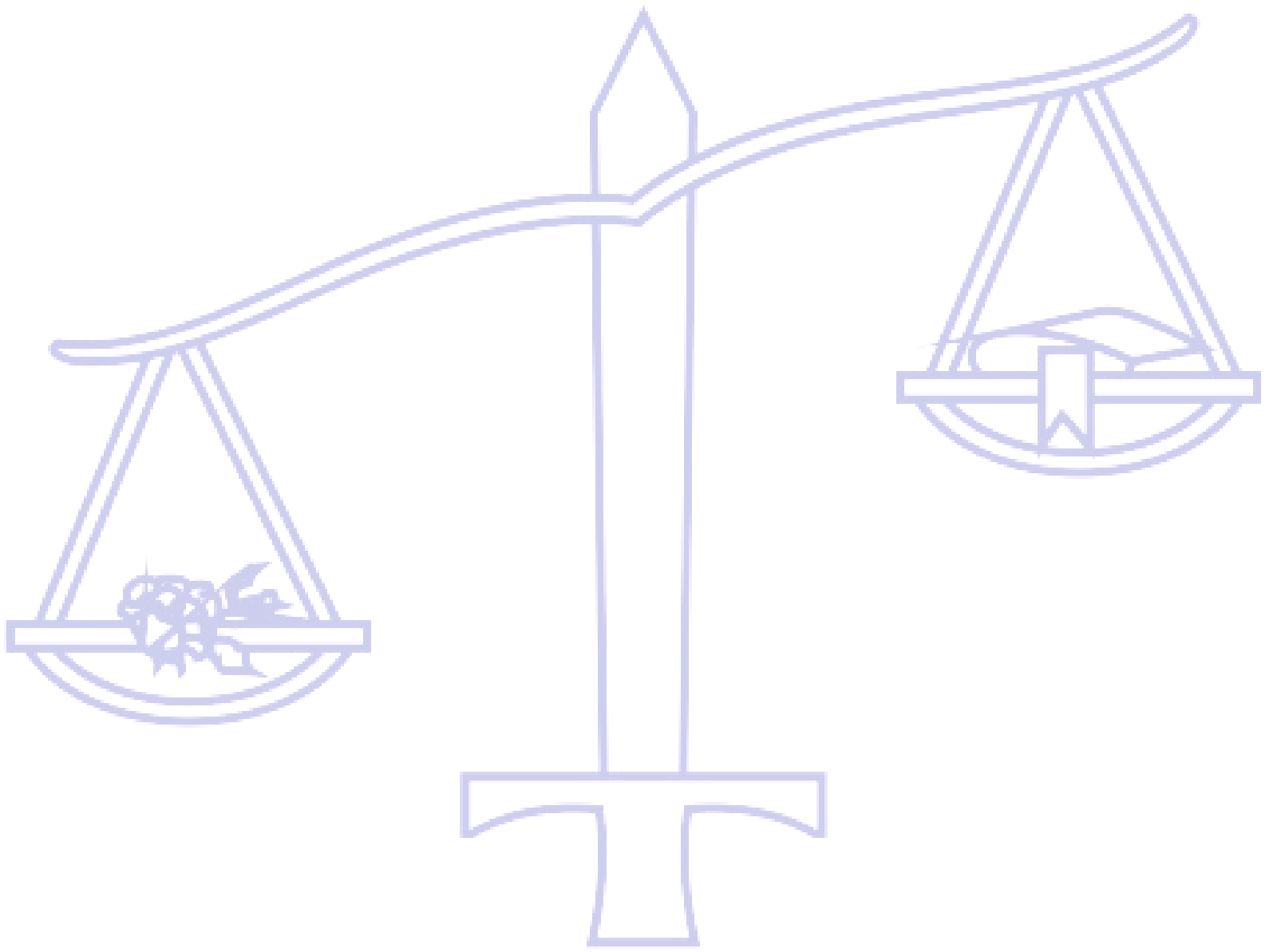




\section{Introdução}

O fenômeno da urbanização acentuada é sensível no mundo todo, o que tem provocado uma maior conscientização, inclusive em nível internacional, acerca da importância do tratamento da questão urbana para o futuro da humanidade. Nesse sentido, apesar de os problemas advindos do crescimento acelerado das cidades serem de diferentes grandezas dependendo do "nível" do país em questão, é possível perceber um consenso generalizado de que é necessário estabelecer, de forma consistente, políticas urbanas capazes de conciliar as distintas demandas que se apresentam em cidades inseridas num mundo cada vez mais complexo.

No que diz respeito aos países periféricos, mais precisamente o Brasil, o que se constata, para além do crescente processo de urbanização, é o desenvolvimento desordenado das cidades, que resulta em um cenário desigual tanto no que diz respeito à constituição do seu espaço urbano quanto no que se refere aos seus aspectos sociais. De fato, esse ritmo de urbanização acentuado não ocorre sem deixar marcas, pois a passagem para uma população predominantemente urbana acarretou a expansão periférica e precária das cidades.

Cumpre destacar, contudo, que essa explosão urbana não é o único fator responsável pelo cenário caótico e desigual com o qual nos deparamos atualmente nas cidades brasileiras. Há que se ter presente que o processo de industrialização propulsor da urbanização brasileira (notadamente a partir da década de 1940) ${ }^{1}$ não incluiu, no valor dos salários, o custo da “mercadoria habitação". O então novo cidadão urbano, operário da indústria brasileira, não ganha o suficiente para pagar o preço da moradia fixado pelo chamado mercado formal. Aliado a isso, a legislação urbanística e fundiária sempre se mostrou de tal forma exigente e complexa que criou um padrão de uso e ocupação do solo que, ao lado de políticas e investimentos públicos destinados ao setor mais abastado e "promissor" da cidade, fomentou a especulação fundiária. Por conseguinte, restou obstaculizado o acesso formal à moradia pela população de baixa renda. (MARICATO, 2000, p. 158)

O produto dessa equação são os assentamentos periféricos, informais e precários dessa nova parcela da população urbana, para quem não foram garantidas as condições de uma

1 Consoante Milton Santos (1994, p. 27), o termo 'industrialização' não pode ser tomado em sentido estrito, tão somente como a criação de atividades nos lugares, mas sim no seu significado mais amplo, enquanto processo social complexo, onde se incluem a formação de um mercado nacional, os esforços de equipamento do território para torná-lo integrado, como a expansão do consumo em diversas frentes, impulsionando a vida de relações e ativa do próprio processo de urbanização. 
moradia minimamente digna. A proliferação de processos informais de desenvolvimento urbano apresenta-se, assim, como uma das principais características da urbanização brasileira, na medida em que o planejamento urbano no Brasil sempre foi descomprometido com a realidade social, gerando uma situação de segregação espacial e social urbana de dimensões assustadoras.

O reconhecimento dessa realidade é condição sine qua non para que se possa iniciar um processo de transformação nas cidades. Para tanto, previsões normativas não são mais suficientes (e pelo visto nunca foram), impondo-se uma abordagem que, para além da dogmática jurídica, inclua os aspectos que façam diferença na elaboração de uma política pública de regularização fundiária cujo objetivo é a efetivação do direito à moradia minimamente digna.

A partir dessa ótica, o presente trabalho buscará demonstrar a importância da transdisciplinaridade na política pública de regularização fundiária/como condição de efetividade do direito à moradia minimamente digna nos assentamentos urbanos informais. Para isso se analisará, de início e ainda que perfunctoriamente, a questão do mínimo existencial como pressuposto da dignidade da pessoa humana no direito à moradia. Após, será apresentado, brevemente, um panorama sobre a política pública de regularização fundiária no Brasil. Finalmente, será abordada a metodologia transdisciplinar no contexto da política pública de regularização fundiária.

\section{A dignidade da pessoa humana, no direito à moradia, a partir das condições mínimas} de habitabilidade

O surgimento do tratamento dogmático sobre uma garantia fundamental às condições fáticas e materiais que assegurem uma vida minimamente digna é atribuído à Alemanha. $\mathrm{Na}$ doutrina deste país, o assunto começou a ter tratamento de peso com Otto Bachof que, no início da década de 1950, destacou que o princípio da dignidade da pessoa humana demanda, para além do direito de defesa, um mínimo de segurança social, pois a ausência de recursos materiais para uma existência digna compromete a própria dignidade da pessoa humana (SARLET, 2006, p. 564).

Na Constituição Federal de 1988, o mínimo existencial não está consagrado em uma disposição normativa específica. É inerente à pessoa humana, surgindo num patamar pré- 
constitucional, e, como tal, condiciona a ordem jurídica (TORRES, 1989, p. 32), norteando a interpretação de cláusulas constitucionais que estejam conectadas aos direitos fundamentais, tal como é o caso da dignidade da pessoa humana.

Nesses termos, a dignidade da pessoa humana está intrinsecamente associada à satisfação de parcelas mínimas materiais que são protegidas pelos direitos sociais, tal como é o direito à moradia, pois esses direitos servem para atender à igualdade e à liberdade material, “objetivando, em última análise, a proteção da pessoa contra as necessidades de ordem material e à garantia de uma existência com dignidade" (SARLET, 2003, p. 208). Com efeito, na estrutura do mínimo existencial encontra-se a dignidade da pessoa humana, o que caracteriza o mínimo existencial não somente como o "conjunto de prestações suficientes apenas para assegurar a existência (a garantia da vida) humana, mas, mais do que isso, uma vida com dignidade" (SARLET, 2007, p. 95).

A Constituição Federal de 1988, em seu artigo $1^{\circ}$, inciso III, ao referir, de forma inédita na história do constitucionalismo brasileiro, a dignidade da pessoa humana como fundamento da República e do Estado Democrático de Direito, reflete a preocupação do constituinte em considerar concreta e individualmente cada pessoa como fim precípuo do reconhecimento e da proteção pela ordem constitucional. Além disso, reconhece, cristalinamente, que é o Estado que vive em função da pessoa humana, e não o contrário, na medida em que o ser humano é o fim precípuo da atividade estatal, e não o meio pelo qual atua, expressando, de forma inequívoca, a concepção kantiana de que

[...] o homem - e, de uma maneira geral, todo o ser racional - existe como fim em si mesmo, e não apenas como meio para uso arbitrário desta ou daquela vontade. [...] o imperativo categórico prático será, pois, o seguinte: "age de tal maneira que possas usar a humanidade, tanto em tua pessoa como na pessoa de qualquer outro, sempre e simultaneamente como fim e nunca simplesmente como meio". [...] Todos os seres racionais estão, pois, submetidos a essa lei que ordena que cada um deles jamais se trate a si mesmo ou aos outros simplesmente como meios, mas sempre simultaneamente como fins em si. [...] No reino dos fins, tudo tem ou um preço ou uma dignidade. Quando uma coisa tem preço, pode ser substituída por algo equivalente; por outro lado, a coisa que se acha acima de todo o preço, e por isso não admite qualquer equivalência, compreende uma dignidade. (KANT, 2004, p. 58)

Por tudo isso, é imperiosa a promoção da moradia digna àquelas pessoas que vivem em condições precárias e subnormais nos assentamentos urbanos informais ${ }^{2}$, população esta

2 Assentamentos urbanos informais é o resultado de um processo informal de desenvolvimento urbano. A irregularidade fundiária urbana é a forma com que isso ocorre, ou seja, diz respeito aos distintos processos de 
que restou excluída do perímetro urbano em que são garantidas as condições mínimas de habitabilidade, que caracterizam um padrão de vida digno de uma moradia adequada, considerada como aquela que possui os elementos básicos, mínimos de habitabilidade.

No que diz respeito a esses elementos básicos de habitabilidade ou ao mínimo existencial no direito à moradia, a Agenda Habitat II $^{3}$, que no Brasil foi especialmente orientada aos municípios, preceitua, no seu artigo 60, que

Habitação adequada para todos é mais do que um teto sobre a cabeça das pessoas. É também possuir privacidade e espaço adequados, acessibilidade física, garantia de posse, estabilidade estrutural e durabilidade, iluminação adequada, aquecimento e ventilação, infraestrutura básica adequada, como fornecimento de água, esgoto e coleta de lixo, qualidade ambiental adequada e fatores relacionados à saúde, localização adequada e acessível em relação a trabalho e instalações básicas: tudo deveria ser disponível a um custo acessível. A adequação deve ser determinada juntamente com as pessoas interessadas, considerando-se a perspectiva de desenvolvimento gradual. (FERNANDES, 2003, p. 48-49)

É justamente em virtude de sua estreita ligação com a dignidade da pessoa humana, que o núcleo do direito à moradia pressupõe parâmetros qualitativos mínimos para uma vida decente. Não há dúvidas de que

[...] sem um lugar adequado para proteger-se a si próprio e a sua família contra as intempéries, sem um local para gozar de sua intimidade e privacidade, enfim, de um espaço essencial para viver com um mínimo de saúde e bem estar, certamente a pessoa não terá assegurada a sua dignidade, aliás, por vezes não terá sequer assegurado o direito à própria existência física, e, portanto, o seu direito à vida. (SARLET, 2007, p. 213)

Dessa forma, ao se abordar o direito à moradia digna desde a perspectiva dos assentamentos humanos informais, é inevitável a análise da relação entre a pobreza, a exclusão social e os direitos sociais sob o manto da dignidade da pessoa humana. Uma dimensão dúplice da dignidade lhe coloca, ao mesmo tempo, como a capacidade do indivíduo de autodeterminar-se no que diz respeito às decisões essenciais sobre sua própria existência, e

consolidação dos assentamentos informais, sendo muitos os tipos em que é possível identificá-la: favelas, ocupações de propriedade pública ou privada, loteamentos clandestinos ou irregulares, cortiços (habitações coletivas familiares).

3 A ONU promoveu, em 1996, nos dias 03 a 14 de junho, na cidade de Istambul, Turquia, a II Conferência das Nações Unidas sobre os Assentamentos Humanos, onde foi assinado um documento - o PLANO DE AÇÃO GLOBAL, também chamado de AGENDA HABITAT, cujo escopo é colocar as questões urbanas num lugar prioritário nos programas de desenvolvimento dos países que assinaram esse documento. 
como a necessidade de sua proteção (assistência) por parte da comunidade e do Estado. (SARLET, 2007, p. 61)

De fato, a pobreza não significa, por si só, violação da dignidade (SARLET, 2007, p. 213). Todavia, no momento em que essa pobreza provoca o cerceamento do exercício de autodeterminação da pessoa no que diz respeito aos aspectos básicos de sua vida pela exclusão nos processos de decisões que lhe dizem respeito diretamente, ocorre a violação de um dos aspectos inerentes à moradia adequada, qual seja, a participação na tomada de decisões por aqueles que são diretamente afetados.

No caso da moradia digna, nos termos da Agenda Habitat II para os Municípios brasileiros, a adequação à moradia digna "deve ser determinada juntamente com as pessoas interessadas, considerando-se a perspectiva de desenvolvimento gradual"/(FERNANDES, 2003, p. 48-49), e não simplesmente imposta sem considerar as reais necessidades de adequação da moradia à vida daquelas pessoas diretamente envolvidas.

Para reverter esse quadro, é necessário, portanto, que as políticas urbanas exerçam, concretamente, um papel promotor e amplificador da democracia e da cidadania, a partir da construção de uma consciência da cidade real com as demandas populares. Essa é a premissa para a articulação na direção de uma nova estrutura espacial e social das cidades, pois é isso que permite elaborar novos paradigmas capazes de inverter o processo de deterioração da qualidade de vida nas cidades.

Nesse sentido,

as pessoas devem ter condições dignas de existência, aí incluindo-se a liberdade de desenvolverem-se como indivíduos, a possibilidade de participarem das deliberações coletivas, bem como as condições materiais que as livre da indignidade [...], não apenas porque isso é desejável, mas porque a Constituição, centro do sistema jurídico, norma fundamental e superior, assim determina. (BARCELLOS, 2002, p. 26-27)

É nesse contexto que a política pública de regularização fundiária assume papel de destaque para que a moradia minimamente digna seja assegurada àquela (grande) parcela da população que ocupa os assentamentos urbanos informais. Conforme Amartya Sen, o desenvolvimento é o fortalecimento da liberdade de escolha do indivíduo para levar o tipo de vida que lhe é importante, e isso só é possível se forem garantidas as condições básicas de sobrevivência (SEN, 1988, p. 87). O que ocorre hoje, em vários aspectos, mas visivelmente na 
questão da moradia, é que não há escolha para o cidadão que ocupa um assentamento urbano informal, e sim uma imposição de absoluta exclusão social.

\section{Breve panorama da política pública de regularização fundiária no Brasil}

A política pública de regularização fundiária tem origem recente, e seu surgimento se justifica pelo fato, já mencionado, de que a urbanização no Brasil é permeada por processos informais de desenvolvimento urbano. Isso tem impactado perniciosamente o direito à moradia de uma imensa parcela da população brasileira, cuja precariedade tem alcançado patamares tão alarmantes que a questão passou a ser um problema social, a ser combatido por todos. Dessa forma, tornou-se inevitável o tratamento da regularização fundiária como uma política pública ${ }^{4}$ de combate à informalidade urbana e de todos os efeitos daí decorrentes.

A promulgação da Constituição Federal de 1988 é o marco legal que inaugura a possibilidade dessa política, ao dedicar um capítulo específico à Política Urbana (artigos 182 e 183). Todavia, é com o Estatuto da Cidade (Lei $\mathrm{n}^{\circ}$ 10.257/01) que se estabelece efetivamente um horizonte inédito para o tratamento da questão da regularização fundiária urbana, na medida em que possibilita o seu desenvolvimento ao prever mecanismos capazes de enfrentar os obstáculos trazidos pela própria legislação brasileira (seja ela ambiental, urbanística ou fundiária), erigindo uma nova ordem de ação urbanística mediante o estabelecimento de critérios econômicos, sociais e ambientais para o desenvolvimento da política urbana.

Desde a promulgação da Constituição Federal de 1988 até a edição do Estatuto da Cidade, em 2001, a regularização fundiária era realizada aleatoriamente por algumas cidades e sem sistematização, já que não havia as diretrizes, programas e a possibilidade de ação mais integrada sobre a questão como existe hoje. Essa situação não impediu, contudo, que municípios tomassem certas medidas em relação à questão dos assentamentos urbanos informais, como é o caso de Porto Alegre e Diadema, destaques na década de 1990,

\footnotetext{
4 "Políticas públicas configuram decisões de caráter geral que apontam rumos e linhas estratégicas de atuação governamental, reduzindo os efeitos da descontinuidade administrativa e potencializando os recursos disponíveis ao tornarem públicas, expressas e acessíveis à população e aos formadores de opinião as intenções do governo no planejamento de programas e atividades". In: Documento do Ministério da Saúde: Política nacional de plantas medicinais e fitoterápicos. Brasília, 2006, p. 9 apud SCHMIDT, João Pedro. Gestão de políticas públicas: aspectos conceituais e aportes para um modelo pós-burocrático e pósgerencialista. In: LEAL, Rogério Gesta; REIS, Jorge Renato (Org.). Direitos Sociais e Políticas Públicas: desafios contemporâneos. Santa Cruz do Sul: Edunisc, 2007. tomo 7.
} 
respectivamente, pela melhor legislação e repertório de instrumentos, e pelo melhor fluxograma e integração administrativa. Ressalte-se, todavia, que essas intervenções foram pontuais, e não contaram com o respaldo de uma política pública concretamente elaborada e desenvolvida para esse fim. (ALFONSIN, 2007) ${ }^{5}$

De fato, o tratamento dispensado à regularização fundiária pelos municípios, nesse ínterim, foi permeado por certa vulnerabilidade, pois não havia instrumentos adequados para lidar com a dimensão do problema dos assentamentos urbanos informais; havia insegurança jurídica das iniciativas municipais, além do fato de se utilizar legislação de Direito Privado para solucionar problemas de Direito Público, o que nem sempre se adequava às situações que se apresentavam. Não bastasse, não havia preparo das administrações municipais para tratar, de forma integrada, de uma questão complexa como é a regularização fundiária dos assentamentos urbanos informais. Por último, cabe destacar que as prefeituras não tinham condições para estabelecer diálogo com outras esferas governamentais - estadual e federal -, e tampouco com atores importantes como o Ministério Público, o Poder Judiciário, os Registros de Imóveis e a própria sociedade. (ALFONSIN, 2002, p. 11)

Todavia, após a promulgação da Constituição Federal de 1988, e da inclusão do direito à moradia como direito social em 2000, pela Emenda Constitucional 26/2000, a edição do Estatuto da Cidade, em 2001, não somente apresentou normas para a regularização fundiária como também a inclui na agenda obrigatória da política de desenvolvimento urbano (INSTITUTO POLIS, 2002, p. 11). Em seguida, em 2003, houve a criação do Ministério das Cidades, e que conta, em sua estrutura, com a Secretaria Nacional de Planejamento Urbano, que tem como uma de suas atribuições primordiais a promoção e apoio à regularização fundiária dos assentamentos urbanos informais. Ademais, a participação popular tem tido cada vez maior relevo para os processos de regularização, tanto é assim que a gestão democrática é uma das diretrizes do Estatuto da Cidade. Além disso, a atuação do terceiro setor, principalmente através das ONG's (organizações não governamentais) tem sido bastante forte, como, por exemplo, o trabalho que vem sendo realizado pelo Instituto Polis ${ }^{6}$.

\footnotetext{
ALFONSIN, Betania. A experiência brasileira de regularização fundiária. Apresentação em Workshop de Estudos Urbanos. Disponível em: <http://www.cidades.gov.br/index.php?option=content\&task=category\&id=588>. Acesso em: 21 ago. 2007.

6 Pólis - Instituto de Estudos, Formação e Assessoria em Políticas Sociais é uma Organização Não Governamental de atuação nacional, constituída como associação civil sem fins lucrativos, apartidária, pluralista e reconhecida como entidade de utilidade pública nos âmbitos municipal, estadual e federal. O Instituto Polis conta com uma Relatoria Nacional para o Direito à Moradia Adequada e Terra Urbana, cujo trabalho tem como foco monitorar a implementação do direito à moradia adequada no Brasil. Disponível em: $<$ http://www.polis.org.br>. Acesso em: 6 ago. 2007.
} 
Cabe destacar, outrossim, as recentes mudanças na legislação nacional que visam propiciar a inserção da regularização fundiária na ordem jurídica como um todo, inclusive no que diz respeito às áreas de propriedade da União. Nesse sentido é que a Lei $n^{\circ} 11.481$, de 31 de maio de 2007, que objetiva transpor os obstáculos para regularização fundiária de assentamentos de baixa renda em áreas públicas pertencentes à esfera federal, alterou diversos dispositivos legais para adequar a legislação vigente à nova realidade jurídico-urbanística advinda com a Constituição Federal de 1988 e com a edição do Estatuto da Cidade.

A Lei ${ }^{\circ} 11.977$, de 07 de julho de 2009, alterada pela Lei ${ }^{\circ} 12.424$, de 16 de junho de 2011, trata, especificamente, da questão da regularização fundiária de assentamentos urbanos, esclarecendo e sistematizando aspectos importantes, como o conceito de regularização fundiária (artigo 46) ${ }^{7}$ e a definição de área urbana, área urbana consolidada, demarcação urbanística, legitimação da posse, assentamentos irregulares, regularização fundiária de interesse social e de interesse específico (artigo 47).

Além disso, essa lei introduziu diversos mecanismos facilitadores da regularização fundiária, principalmente na Lei $\mathrm{n}^{\circ}$ 6.015/73, a Lei de Registros Públicos ${ }^{8}$, a fim de estabelecer pontes entre a realidade fática e a realidade registral dos programas de regularização fundiárias executados no âmbito dessa política pública de inclusão social, e, assim, proporcionar uma permeabilidade cada vez maior entre todos os atores envolvidos para a sua plena execução. Veja-se que, nesse sentido, foi inserido, através da Lei no 12.424/2011, um novo capítulo na Lei $\mathrm{n}^{\mathrm{o}}$ 6.015/73 - Lei de Registros Públicos, relativamente ao registro da regularização fundiária urbana (“Capítulo XII - Do Registro da Regularização Fundiária Urbana”), conferindo um procedimento especial para essas hipóteses, a fim de diminuir os obstáculos registrários e facilitar a conclusão da regularização fundiária no Registro de Imóveis.

Como é possível constatar, o panorama que se desenha para a regularização fundiária é o de propiciar cada vez mais condições para sua implementação enquanto política pública de

\footnotetext{
7 "Art. 46. A regularização fundiária consiste no conjunto de medidas jurídicas, urbanísticas, ambientais e sociais que visam à regularização de assentamentos irregulares e à titulação de seus ocupantes, de modo a garantir o direito social à moradia, o pleno desenvolvimento das funções sociais da propriedade urbana e o direito ao meio ambiente ecologicamente equilibrado."

8 A Lei no 11.977/09 inseriu o item 41 no inciso I do artigo 167, para fazer constar o registro da legitimação da posse, e o item 26 no inciso II do mesmo dispositivo legal, acrescentando a averbação do auto de demarcação urbanística. Também o artigo 221, que trata dos títulos admitidos para registro, foi alterado, admitindo para registro, no inciso V, os contratos ou termos administrativos, assinados com a União, Estados e Municípios no âmbito de programas de regularização fundiária, dispensado o reconhecimento de firma, tendo sido alterado pela Lei $\mathrm{n}^{\circ}$ 12.424/2011 para fazer constar também o Distrito Federal e os programas habitacionais de interesse social.
} 
inclusão social para a concretização do direito a uma moradia minimamente digna, de forma a envolver todos os atores responsáveis nesse processo.

\section{Política pública transdisciplinar de regularização fundiária e a efetividade do direito à moradia}

Para que a política pública de regularização fundiária efetivamente promova o direito à moradia, é necessário que seja desenvolvida de forma transdisciplinar, para, assim, superar o estágio de abordagem positivista de mera subsunção dos fatos à lei. Essa concepção positivista propiciou o desenvolvimento de um conhecimento compartimentado, em que a análise se desenvolve de forma fragmentada, gerando uma incapacidade de se enfrentar fenômenos e situações que se apresentem com maior dinamismo, notadamente os sociais, que são naturalmente complexos. De fato, a aplicação de determinado conhecimento sobre um aspecto isolado de um dado fenômeno não proporciona as condições necessárias para sua compreensão.

Se, por um lado, a metodologia positivista facilitou a compreensão do mundo, ao "permitir" a análise fragmentada, por outro, complicou, e muitas vezes inviabilizou, a tomada de decisões em situações mais complexas. Para enfrentar esse paradoxo, foi (e segue sendo) necessária uma visão holística da realidade, mediante o estabelecimento de relações entre as diversas áreas que uma determinada análise comporta para alcançar o objetivo comum, que transcende o fim específico de cada uma das áreas envolvidas.

Sob a ótica transdisciplinar ${ }^{9}$, "há o reconhecimento da existência de diferentes níveis de realidade, regidos por lógicas diferentes" (FREITAS; MORIN; NICOLESCU, artigo 2, da Carta da Transdisciplinaridade $\left.{ }^{10}, 1994\right)$ de forma que a transdisciplinaridade "faz emergir da confrontação das disciplinas dados novos que as articulam entre si” (FREITAS; MORIN; NICOLESCU, artigo 3, da Carta da Transdisciplinaridade, 1994). Com efeito, "a

9 Ensina Roque Theophilo (p. 2), em "A transdisciplinaridade e a modernidade": "O termo transdisciplinaridade não é novo. O termo data de 1970, quando Jean Piaget afirmou durante um congresso sobre interdisciplinaridade, que aquela etapa deveria ser sucedida por uma etapa transdisciplinar. O prefixo trans remete ao que está entre, através e além das disciplinas". Disponível em: <http://www.sociologia.org/tex/ap40.htm>. Acesso em: 3 abr. 2010.

10 "A Carta da Transdisciplinaridade" foi adotada no Primeiro Congresso Mundial de Transdisciplinaridade, realizado no Convento de Arrábida, em Portugual, entre os dias 02 e 06 de novembro de 1994, tendo como autores: Lima de Freitas, Edgar Morin e Basarab Nicolescu. Disponível em: <http://www.sociologia.org.br>. Acesso em: 3 abr. 2010. 
transdisciplinaridade não procura o domínio sobre várias outras disciplinas, mas a abertura de todas elas àquilo que as atravessa e as ultrapassa" (FREITAS; MORIN; NICOLESCU, artigo 3 da Carta da Transdisciplinaridade, 1994).

É justamente esse viés transdisciplinar que deve nortear a política pública de regularização fundiária, ainda incipiente no Brasil. De fato, não é possível afirmar que as experiências havidas tenham sido desenvolvidas transdisciplinarmente, pois, em algum momento, são desconectadas do fio condutor que deve estar sempre presente: a moradia digna com todos os elementos que a contém. Isso ocorre justamente em virtude da lacuna que existe na forma de tratar essa questão, que vai muito além dos aspectos jurídicos, urbanos e fundiários. "O saber fragmentado resolve diretamente as questões menores, suscitadas na vida prática. Por isso, proliferam a ociosidade e a negligência em relação à abordagem do saber genérico, pois este não oferece resultados imediatos que sejam de fácil apuração e utilização" (KORTE, 2004, p. 50).

Veja-se que a Lei $n^{\circ} 11.977 / 2009$, em seu artigo 46, traz todos os elementos necessários para que a abordagem ocorra de forma transdisciplinar, pois o dispositivo mencionado refere que além das medidas jurídicas e urbanísticas, devem compor o conjunto medidas ambientais e sociais, a fim de regularizar os assentamentos irregulares e proporcionar a titulação de seus ocupantes, "de modo a garantir o direito social à moradia, o pleno desenvolvimento das funções sociais da propriedade urbana e o direito ao meio ambiente ecologicamente equilibrado".

Nesse contexto, a fim de ilustrar a necessidade de uma abordagem transdisciplinar na aplicação do artigo 46 da Lei $n^{\circ} 11.977 / 2009$ no desenvolvimento da regularização fundiária urbana para efetivação do direito à moradia, é imperioso diferenciar, a partir do Modelo de Jantsch, citado por Roque Theophilo (THEOPHILO, 2010, p. 22), os institutos da multidisciplinaridade, interdisciplinaridade e transdisciplinaridade.

Na multidisciplinaridade, verifica-se que há uma diversidade de disciplinas em torno de um conteúdo comum, mas sem qualquer cooperação entre elas, ou seja, é um sistema de um só nível, com objetivos múltiplos, mas sem interligação ou qualquer tipo de relacionamento entre as disciplinas que gravitam ao redor de um tema comum. Observa-se, assim, que a abordagem multidisciplinar é totalmente incompatível com a ideia da regularização fundiária urbana para efetivação do direito à moradia, em virtude das inúmeras facetas que envolvem a moradia digna, e que, necessariamente, pressupõe uma dinâmica de 
relação entre os distintos aspectos, sob pena de se garantir a titulação, por exemplo, mas não o acesso ao saneamento básico, ou ao custo acessível, e assim sucessivamente.

Já na interdisciplinaridade, embora haja, em um nível inferior, cooperação entre as disciplinas, há a necessidade de um nível superior que provê a forma pela qual essas disciplinas devem relacionar-se. Levando em consideração o disposto no artigo 46 da Lei n $^{\circ}$ 11.977/2009, especialmente a afirmação de que a regularização fundiária consiste "no conjunto de medidas jurídicas, urbanísticas, ambientais e sociais", e que cada uma dessas esferas conta com um nível superior específico, ainda que em cada uma delas os conhecimentos se relacionassem, no todo isso não aconteceria, pois dependeria de um nível superior aos níveis superiores de cada uma delas, o que é inviável até mesmo pela estrutura administrativa na qual cada área envolvida encontra-se organizada.

A título de ilustração, haveria interdisciplinaridade dentro da esfera jurídica, na qual participariam, exemplificativamente, o Registro de Imóveis e a Prefeitura, ambos "subordinados" à legislação respectiva, enquanto na esfera social haveria outro tipo de interação "subordinada" às questões dos ocupantes, tais como a necessidade de escolas, hospitais, transporte público, etc, na cercania do local onde fosse realizada a regularização fundiária. Veja-se que, ainda que haja uma relação interdisciplinar dentro de cada esfera, isso não ocorre entre essas esferas. É justamente nesse ponto que a transdisciplinaridade surge como a alternativa de abordagem propícia para buscar efetivar o direito à moradia com todos os seus elementos mínimos para uma habitação condigna, permitindo que os aspectos setoriais se coordenem, simultaneamente, para um objetivo comum.

Assim, consoante já referido neste trabalho, considerando que, na transdisciplinaridade, "o prefixo trans remete ao que está entre, através e além das disciplinas" (THEOPHILO, 2010, p. 2), a transdisciplinaridade atua interligando todas as esferas (jurídica, urbanística, ambiental e social), que devem coordenar-se e cooperar-se entre si a partir de um eixo integrador, que, ao que se propõe o presente trabalho, seria justamente o direito à moradia com seus elementos mínimos para uma vida digna, obrigando a uma percepção global do que deve ser feito. Consoante Jantsch, citado por Roque Theophilo, a transdisciplinaridade caracteriza-se por um "sistema de níveis e objetivos múltiplos; coordenação com vistas a uma finalidade comum dos sistemas” (THEOPHILO, 2010, p. 5).

Nesse sentido, o tratamento transdisciplinar forçaria que a regularização fundiária urbana de determinada área não negligenciasse em nenhum dos aspectos que a compõem (jurídico, urbanístico, ambiental e social), aspectos esses que devem considerar a dignidade da 
moradia daqueles que habitam aquele local, incluindo-se o direito dessas pessoas à participação para a tomada de decisões, que é o que, efetivamente, legitimaria, ao fim e ao cabo, a realização da referida regularização fundiária, pois são essas pessoas que detêm a memória e o histórico das razões que originaram a situação de irregularidade a ser sanada.

No Brasil, o atual Programa Minha Casa Minha Vida (PMCMV) é o principal meio de atuação do Estado para efetivar o direito à moradia, e deve ser norteado, consoante as normas internacionais adotadas pelo Brasil para uma moradia adequada, pelos elementos essenciais que a compõem: habitabilidade; disponibilidade de serviços, infraestrutura e equipamentos públicos; localização adequada; adequação cultural; acessibilidade; segurança da posse; e custo acessível. Esse programa conta com forte participação do setor empresarial, de maneira que "se é possibilitado às construtoras decidirem em grande parte onde, como e quando pretendem produzir unidades habitacionais, é preciso averiguar se os padrões estabelecidos internacionalmente para o direito à moradia adequada estão orientando essa produção". (ROLNIK et al, 2015, p. 392).

A fim de verificar se esse programa federal efetiva o direito à moradia adequada, foi realizado, pelo LabCidade - FAU - USP, um levantamento no qual foram avaliados sete empreendimentos do Programa Minha Casa Minha Vida, no estado de São Paulo, para famílias com renda mensal de até R\$ 1.600,00 (ROLNIK et al, 2015, p. 392).

A partir da análise de cada um dos aspectos de uma moradia digna, a conclusão do estudo de caso foi de que "parece possível afirmar que a produção habitacional através do PMCMV apresenta tanto avanços quanto problemas do ponto de vista dos padrões internacionais estabelecidos para a efetivação do direito à moradia adequada" (ROLNIK et al, 2015, p. 413).

Com efeito, conclui o estudo realizado que

o princípio da indivisibilidade norteia o respeito, a garantia e a efetivação dos direitos humanos no plano internacional, ou seja, a rede de proteção formada pelos direitos humanos é indivisível, sendo a fruição de cada direito afetada diretamente pela situação de efetivação ou violação de outros direitos. Nesse sentido, a plena efetivação do direito à moradia adequada relaciona-se diretamente com a concretização de outros direitos, como o direito à saúde, ao trabalho, à assistência social, à educação, à não discriminação e assim por diante. (ROLNIK et al, 2015, p. 415) 
Veja-se que uma abordagem transdisciplinar da regularização fundiária para a efetivação do direito à moradia almeja justamente atender todas as nuances relacionadas a esse direito fundamental, pois "o direito à moradia não pode ser adequadamente concretizado sem que sejam atendidos outros direitos fundamentais" (ROLNIK et al, 2015, p. 415).

O que há, repita-se, em termos de política pública de regularização fundiária no Brasil, é um horizonte novo que se apresenta com muitas possibilidades de concretização, mas que dependerá, basicamente, da forma com que esta política será desenvolvida. Nessa esteira, nada adiantará possuir todo o ferramental antes descrito se, na sua elaboração e no seu desenvolvimento, o tratamento for compartimentado, fragmentado e dissociado de todo o histórico que deu margem àquela situação de irregularidade.

Em tal contexto, o plano diretor exerce papel fundamental, pois o seu processo de elaboração e aprovação oferece "uma oportunidade única para que o tratamento da questão da regularização fundiária de assentamentos informais se dê de maneira integrada e articulada com o planejamento urbano e territorial do município como um todo" (FERNANDES, 2005), de forma a contemplar as medidas adequadas à efetivação do direito à moradia digna em um contexto amplo. Dessa forma, a abordagem transdisciplinar deve reinar desde o início do processo de elaboração do plano diretor, passando por sua aprovação e, principalmente, na sua execução para, assim, refletir no desenvolvimento da regularização fundiária.

Há que se ter presente que os assentamentos urbanos informais têm distintas causas, e trazem diferentes impactos em cada cidade e em cada caso de irregularidade, não havendo um modelo único de regularização que seja válido e eficaz para toda e qualquer situação de irregularidade. A compreensão da natureza e da dinâmica dos processos sociais, econômicos, políticos e jurídicos que produzem a informalidade é a base para a formulação, implementação e avaliação dos programas de regularização para o desenvolvimento de políticas efetivas para a moradia digna em cada situação dada de assentamento urbano informal.

Com efeito, a questão da moradia não pode ser tratada de forma desvinculada de todos os aspectos que a rodeiam, tais como pobreza, emprego, educação, saúde, meio-ambiente, violência, para citar os mais evidentes. Isso requer uma gestão integral da política pública de regularização a fim de que haja uma melhora efetiva na qualidade de vida das pessoas que habitam os assentamentos urbanos informais. Distintos setores, coerentemente articulados, devem formar parte de uma política pública de regularização fundiária. 
Assim, por exemplo, no que diz respeito à saúde, deve haver, para além da regularização jurídica e urbanística da área, todo um projeto de inserção e colocação de serviços básicos como água, esgoto e postos de saúde. Da mesma forma, no que diz respeito à instalação de creches, ao desenvolvimento de locais e alternativas de geração de trabalho na própria comunidade, ao acesso a transportes públicos, e assim por diante. Deve-se buscar melhorias na qualidade de vida dessas pessoas através da elaboração e da execução de uma política pública de regularização fundiária equilibrada e sustentável, assegurando as condições mínimas de habitabilidade para o desenvolvimento de uma vida digna, de forma a efetivar o direito humano fundamental social à moradia de que dispõem os tratados internacionais e a Constituição Federal brasileira.

A política de regularização deve, ainda, procurar antecipar os impactos urbanos e sociais pós-regularização e estabelecer uma estratégia em relação a eles, principalmente no que se refere ao mercado, que tem influência direta no acesso à cidade. Se a regularização, ao retirar os lotes e unidades habitacionais do mercado informal e inseri-los no mercado imobiliário formal, o fizer sem maiores proteções, a população do assentamento pode ser expulsa pela própria ação do mercado, e as famílias desalojadas vão produzir irregularidade em outros locais da cidade (INSTITUTO POLIS, 2002, p. 143). Salienta-se, desde já, que este risco é inerente ao processo de regularização fundiária que pretende efetivar o direito à moradia, por mais paradoxal que pareça. Todavia, ele pode ser reduzido se a política pública de regularização contemplar de forma transdisciplinar os aspectos que lhe afetam.

O reconhecimento da dignidade dessas pessoas começa pela sua inclusão em todas as dimensões que compõem a moradia na cidade, e isso somente é possível de ser alcançado através de uma metodologia transdisciplinar, na medida em que esta é o "caminho que ultrapassa e transcende as disciplinas, possibilitando resultados integrados, que excedem o conhecimento proporcionado por cada uma delas", incluindo "as informações prestadas pelos mais diversos campos de conhecimentos específicos" (KORTE, 2004, p. 38).

A efetivação do direito à moradia digna só se apresenta possível através de um projeto transdisciplinar, em que a cooperação entre os diferentes aspectos é tão forte que não há como separá-los se o objetivo é proporcionar a moradia minimamente digna nos assentamentos urbanos informais, pois a "transdisciplinaridade sugere uma aquisição de conhecimentos que excede o propiciado pelas demais tecnologias" (KORTE, 2004, p. 38).

Segundo Piaget (apud KORTE, 2004, p. 43), a interdisciplinaridade seria uma forma de se chegar à transdisciplinaridade, etapa que não ficaria na interação e reciprocidade entre 
as ciências, mas alcançaria um estágio onde não haveria mais fronteiras entre as disciplinas. Para isso, impõe-se uma atitude de busca, envolvimento, compromisso e reciprocidade diante dos diferentes setores envolvidos na concretização da dignidade da pessoa humana no direito à moradia daqueles que habitam os assentamentos urbanos informais, pois "o todo é muito mais que a soma das parcelas que o compõem" (KORTE, 2004, p. 45).

\section{Considerações finais}

O crescente ritmo de urbanização acentuado, impulsionado por um processo de industrialização que absorveu somente parte dos cidadãos urbanos, juntamente com legislações e gestões públicas excludentes, resultou na existência de duas cidades dentro de uma só: a cidade formal/regular/oficial e a cidade informal/irregular/clandestina, ao que Borja e Castells chamam de "dualidade intrametropolitana" (BORJA; CASTELLS, 2000, p. 57).

As condições de moradia não são as mesmas para todos os habitantes. Com efeito, grande parte da população urbana não tem acesso à cidade formal/regular/oficial, sendo obrigada a ocupar áreas muitas vezes de risco, sem qualquer infraestrutura e saneamento, onde não há as mínimas condições de habitabilidade, em flagrante violação do direito fundamental à moradia e, sobretudo, do princípio da dignidade da pessoa humana. A moradia adequada é, sem dúvida, um dos elementos mínimos que o indivíduo necessita para o desenvolvimento de uma vida digna, na medida em que a sobrevivência na cidade começa no acesso a uma habitação decente.

O reconhecimento dessa situação é o ponto de partida para que as políticas públicas urbanas sejam democráticas e integradoras, através da participação do cidadão num processo amplo de discussão acerca das reais necessidades urbanas. De fato, o que se constata é que o tratamento dispensado pelo Poder Público a essas situações de irregularidade e informalidade urbana jamais se ateve às peculiaridades desses fenômenos, desconsiderando a heterogeneidade típica dessa anomalia social. Por óbvio, qualquer previsão legal ou eventual intervenção nessas situações não tiveram a ressonância prática esperada e necessária para o enfrentamento do problema.

Sempre se fez (e ainda se faz) necessário que à dimensão urbanística e fundiária sejam agregados outros componentes cruciais para o desenvolvimento de uma política de regularização fundiária inclusiva e efetivadora do direito à moradia digna nos assentamentos 
urbanos informais, para possibilitar uma dinâmica multissetorial integrada. Nesse sentido, cumpre repisar que uma política desse porte deve buscar absorver todas as questões que afetam as condições de vida daquela população em que se está realizando a regularização fundiária (situação das condições da habitação, de saúde, do meio-ambiente, de trabalho, da violência, de transporte, entre outros).

Com efeito, "existe uma situação de fato, em que a destruição planetária se amplifica e a pobreza cresce sem que surja a mínima alteração nos conceitos, em nossa maneira de administrar a realidade" (RANDOM, 2002, p. 28). É necessário, portanto, romper com esse paradigma fragmentário de conhecimento e análise dos fenômenos sociais, o que é possibilitado pela transdisciplinaridade.

É nesse sentido que a política pública de regularização fundiária para o enfrentamento do problema da moradia digna nos assentamentos urbanos informais deverá ser desenvolvida, pois somente desta forma será possível garantir o exercício sustentável deste direito, ainda que essa política pública não elimine, por inteiro, o risco de mobilidade dessas pessoas no futuro.

Convém ressaltar, todavia, que a mobilidade resultante de políticas públicas em certas áreas não deve, em si, ser necessariamente tida como algo negativo, pois ela reflete, antes de tudo, uma acomodação das populações às novas condições físicas, legais e urbanísticas do território. Essa constatação é importante para avaliar os impactos advindos com a regularização nas características socioespaciais das comunidades objeto do programa, e também para definir uma política de acompanhamento desses assentamentos (RANDOM, 2002, p. 28), sempre na tentativa de incluir o excluído.

\section{La transdisciplinariedad en el desarrollo de la política pública de la regularización fundiaria: condición de eficacia del derecho a la vivienda en los asentamientos urbanos informales}

Resumen: El grave problema de la vivienda en los asentamientos urbanos informales es resultado de décadas de desarrollo urbano desigual, debido a la búsqueda de vivienda urbana por la población carente. Mientras haya ocurrido sin atención a la ley urbanística, el gobierno 
y la sociedad no estuvieron sensibilizados para tomar medidas necesarias para evitar la situación consolidada y caótica que hoy son los grandes centros urbanos. A las personas que viven en estos asentamientos no fueron garantizadas condiciones para una vivienda digna, por eso las ciudades brasileñas son la cuna de la desigualdad y de la segregación social y urbana. Los programas oficiales de financiación de vivienda, a su vez, fueron insuficientes, pues actúan según el mercado, inaplicable a la población carente. Así, la regularización fundiaria urbana surge como la alternativa más coherente para hacer frente a estos males. Sin embargo, debe ser elaborada y desarrollada teniendo en cuenta requisitos mínimos de habitabilidad, que involucra aspectos materiales de la vivienda y subjetivos de los moradores. Por consiguiente, la elaboración y el desarrollo de la política de regularización fundiaria urbana debe ser transdisciplinario, con el protagonismo de la población involucrada. Así, la hipótesis que se desarrollará en este trabajo es que la política de regularización fundiaria urbana llevada a cabo desde la perspectiva de la transdisciplinariedad es requisito para la protección y promoción efectiva del derecho a la vivienda mínimamente digna en los asentamientos urbanos informales. El método utilizado para el trabajo fue el deductivo, mediante investigación de literatura y legislación.

Palabras clave: Efectividad del derecho a la vivienda. Regularización fundiaria urbana. Transdisciplinariedad.

\section{REFERÊNCIAS}

ALFONSIN, Betania. A experiência brasileira de regularização fundiária. Apresentação em Workshop de Estudos Urbanos. Disponível em:

$<$ http://www.cidades.gov.br/index.php?option=content\&task=category\&id=588>. Acesso em: 21 ago. 2007.

BARCELOS, Ana Paula de. A eficácia jurídica dos princípios constitucionais: o princípio da dignidade da pessoa humana. Rio de Janeiro: Renovar, 2002.

BORJA, Jordi; CASTELLS, Manuel. Local y Global: la gestión de las ciudades en la era de la información. Madrid: Grupo Santillana Ediciones S.A, 2000.

BRASIL. Código Civil. Lei no 10.406, de 10 de janeiro de 2002. Disponível em: <http://www.planalto.gov.br/ccivil_03/leis/2002/110406.htm>. Acesso em: 10 jan. 2015. 
Constituição da República Federativa do Brasil (1988). Disponível em:

$<$ http://www.planalto.gov.br/ccivil_03/constituicao/constituicaocompilado.htm>. Acesso em: 10 jan. 2015.

Estatuto da Cidade. Lei no 10.257 , de 10 de julho de 2001. Disponível em:

<http://www.planalto.gov.br/ccivil_03/leis/leis_2001/110257.htm>. Acesso em: 10 jan. 2015.

Lei no 6.015, de 31 de dezembro de 1973. Dispõe sobre os registros públicos, e dá outras providências. Disponível em:

<http://www.planalto.gov.br/ccivil_03/leis/L6015compilada.htm>. Acesso em: 10 jan. 2015.

Lei no 11.977, de 7 de julho de 2009. Dispõe sobre o Programa Minha Casa, Minha Vida - PMCMV e a regularização fundiária de assentamentos localizados em áreas urbanas; altera o Decreto-Lei ${ }^{\circ} 3.365$, de 21 de junho de 1941, as Leis $n^{\text {os }} 4.380$, de 21 de agosto de 1964, 6.015, de 31 de dezembro de 1973, 8.036, de 11 de maio de 1990, e 10.257, de 10 de julho de 2001, e a Medida Provisória no 2.197-43, de 24 de agosto de 2001; e dá outras providências. Disponível em: <http://www.planalto.gov.br/ccivil_03/_ato2007-

2010/2009/lei/l11977.htm>. Acesso em: 10 jan. 2015.

FERNANDES, Edésio. A regularização fundiária no coração dos planos diretores: eis o desafio! Boletim Eletrônico IRIB, São Paulo, n. 1635, 24 mar. 2005. Disponível em: <http://irib.org.br/boletins/detalhes/2192>. Acesso em: 10 jan. 2015.

FERNANDES, Marlene. Agenda Habitat para Municípios. Rio de Janeiro: IBAM, 2003.

FREITAS, Lima de; MORIN, Edgar; NICOLESCU, Basarab. A Carta da

Transdisciplinaridade. Portugal, 1994. Disponível em: <http://www.sociologia.org.br>.

Acesso em: 3 abr. 2010.

INSTITUTO POLIS. Regularização da terra e moradia: o que é e como implementar. São Paulo: Instituto Pólis, 2002.

KANT, Immanuel. Fundamentação da Metafísica dos Costumes e outros escritos. São Paulo: Martin Claret, 2004.

KORTE, Gustavo. Metodologia e transdisciplinaridade. São Paulo: Núcleo de Estudos Superiores Transdisciplinares, 2004. Disponível em:

<http://www.gustavokorte.com.br/publicacoes/ >. Acesso em: 10 jan. 2015. 
MARICATO, Ermínia. A cidade do pensamento único: desmanchando conceitos. Petrópolis: Vozes, 2000.

RANDOM, Michel. O território do olhar. In: SOMMERMAN, Américo; MELLO, Maria F. de; BARROS, Vitória M. de (Org.). Educação e transdisciplinaridade II. São Paulo: TRIOM, 2002.

ROLNIK, Raquel et al. Inserção urbana no PMCMV e a efetivação do direito à moradia adequada: uma avaliação de sete empreendimentos no estado de São Paulo. In: Minha casa... e a cidade? Avaliação do programa minha casa minha vida em seis estados brasileiros. AMORE, Caio Santo; RUFINO, Maria Beatriz Cruz; SHIMBO, Lúcia Zanin (Org.). Rio de Janeiro: Letra Capital, 2015.

SANTOS, Milton. A urbanização brasileira. São Paulo: Hucitec, 1994.

SARLET, Ingo Wolfgang. Dignidade da pessoa humana e direitos fundamentais na Constituição Federal de 1988. Porto Alegre: Livraria do Advogado, 2007.

Direitos fundamentais sociais, "mínimo existencial" e direito privado: breves notas sobre alguns aspectos da possível eficácia dos direitos sociais nas relações entre particulares. In: GALDINO, Flávio; SARMENTO, Daniel (Org.). Estudos em homenagem ao professor Ricardo Lobo Torres. Rio de Janeiro: Renovar, 2006.

O Direito Fundamental à Moradia na Constituição: algumas anotações a respeito de seu contexto, conteúdo e possível eficácia. Revista de Direito do Consumidor, São Paulo, n. 46, 2003.

SCHMIDT, João Pedro. Gestão de políticas públicas: aspectos conceituais e aportes para um modelo pós-burocrático e pós-gerencialista. In: LEAL, Rogério Gesta; REIS, Jorge Renato (Org.). Direitos Sociais e Políticas Públicas: desafios contemporâneos. Santa Cruz do Sul: Edunisc, 2007. tomo 7.

SEN, Amartya. Development as freedom. New York: Knopf, 1988.

THEOPHILO, Roque. A transdisciplinaridade e a modernidade. Disponível em: <http://www.sociologia.org.br/tex/ap40.htm>. Acesso em: 3 abr. 2010.

TORRES, Ricardo Lobo. O mínimo existencial e os direitos fundamentais. Revista de Direito Administrativo, Rio de Janeiro, v. 177, p. 29-49, jul./set. 1989. 